\title{
Roux-en-Y Anastomosis
}

National Cancer Institute

\section{Source}

National Cancer Institute. Roux-en-Y Anastomosis. NCI Thesaurus. Code C51756.

Gastric bypass procedure in which part of the stomach is closed off with staples, and part

of the small intestine is bypassed. This procedure is performed in severely obese

patients, for permanent weight loss. 